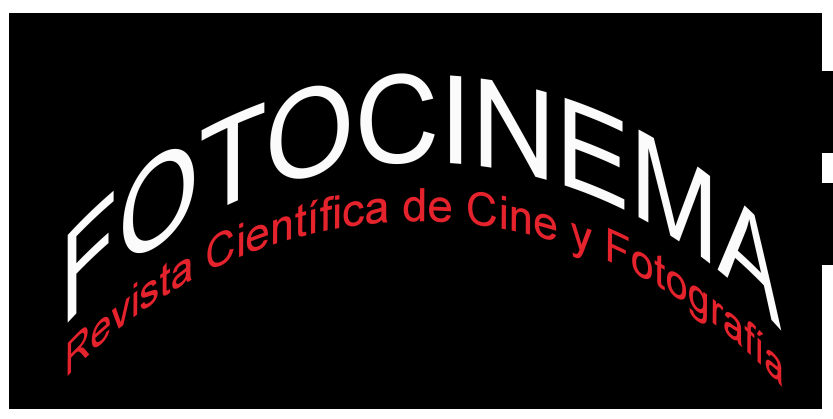

\title{
EL HISTORIADOR Y LA FOTOGRAFÍA: UNA RELACIÓN ANTROPOLÓGICA
}

\section{THE HISTORIAN AND THE PHOTOGRAPHY: AN ANTHROPOLOGICAL RELATIONSHIP}

\author{
Emilio Luis Lara López \\ IES El Valle, Jaén, España \\ emijaen@yahoo.es
}

\section{Resumen:}

Una vez superada la necesaria fase de la fotohistoria, de la historia de la fotografía, era fundamental pasar a escribir historia con fotografías, a través de la fotografía como fuente documental. Este paso aún no se ha dado satisfactoriamente en el ámbito académico. Los historiadores ya conocen las posibilidades documentales de las imágenes. Las fotografías reciben un adecuado tratamiento documental y archivístico, pero los investigadores se siguen resistiendo a incorporarlas como fuente principal en sus trabajos. El historiador que quiera utilizar fotografías de los siglos XIX y XX requiere una sólida formación, pues debe manejar con soltura diferentes corrientes historiográficas y poseer conocimientos de antropología visual.

En este artículo ofrecemos la posibilidad de avanzar hacia la construcción de un modelo histórico de narración visual aplicado al uso de la fotografía como documento histórico.

\begin{abstract}
:
Once we have overcome the required phase of the photohistory, that is, the history of photography, it was essential to write history with photographs, through photography as a documentary source. This step has not succeeded in the academic field yet. The historians are still aware of the wide documentary chances of images. The photographs own a suitable documentary and longterm storage treatment, but the researchers still reject to include them as a main source of their work. The historians who want to use photographs from XIX and XX century need solid academic training, as they must manage different historiographic schools of thought skillfully, and they must be aware of visual anthropology.

In this article, we offer the historians the possibility to move forward to the construction of an historical model of visual narrative applied to the use of the photography as a historical document.
\end{abstract}

Palabras clave:

Historia visual; fotografía; historiografía; antropología; narrativa histórica.

Keywords:

Visual History; Photography; Historiography; Antropology, Historic Narrative. 


\section{Introducción}

El alumbramiento del s. XXI trajo consigo un goteo constante de artículos, capítulos de manuales, libros y ponencias que reivindicaban la necesidad del uso de la fotografía como documento. Estos trabajos coincidían en que las fotografías debían de situarse al mismo nivel que el resto de fuentes documentales tradicionales, y para ello, insistían en que había que hacer historia con fotografías, que éstas fuesen los documentos principales.

Bastantes de las antedichas publicaciones, sobre todo las realizadas por historiadores profesionales, tenían en común su altura científica, pues elaboraban una teoría y una metodología aptas para ser aprovechadas a la hora de enfrentarse con imágenes fotográficas. Sin embargo, las investigaciones históricas que usan prioritariamente fotografías para escribir historia siguen siendo muy pocas, y eso porque "el historiador piensa que las imágenes resultan atractivas e interesantes, incluso impactantes, pero para contar la historia en serio, es decir, para hacer historia de verdad lo que vale es la palabra” (Díaz Barrado, 2012: 142).

\section{La superación de la fotohistoria}

A lo largo de las dos últimas décadas del s. XX se acometió en gran medida el estudio de la historia de la fotografía en España en tres niveles: nacional, autonómico -o regional- y provincial (o local). Esta triple división del ámbito de estudio no es caprichosa, sino que coincide con la estructura estatal española y con el florecimiento de universidades, centros de investigación y organismos (muchos dependientes de las Diputaciones Provinciales y entes autonómicos) que financiaron y alentaron la publicación de estudios históricos conducentes a conocer los rasgos distintivos de cada comunidad autónoma, provincia o localidad. Todo ello animó a muchos historiadores profesionales a fabricarse un currículum académico en el campo de la microhistoria: plantear sus investigaciones en un reducido ámbito geográfico (el de su lugar de nacimiento o en el que desarrollaban su carrera 
profesional), pues -históricamente hablando- había multitud de terrenos vírgenes y existían fuentes documentales archivísticas a su alcance para ser estudiadas con el debido rigor científico. Y en este contexto, la historia de la fotografía -fotohistoria-, encontró, cómo no, un filón.

Los manuales y libros sobre historia de la fotografía (de diferentes países o de España) fueron el esquema básico que los investigadores emplearon en sus respectivos estudios, siendo lo más interesante de la mayoría de estas publicaciones el corpus documental, el listado de operadores fotográficos profesionales o aficionados del s. XIX y comienzos del s. XX, su aportación en la salvaguarda del patrimonio histórico y su ayuda para concienciar a los poderes públicos de la necesidad de conservar el legado fotográfico.

Era necesario acometer dichas investigaciones fotohistóricas ${ }^{1}$. Pero una vez realizadas, urgía dar un paso más: utilizar las fotografías como documentos visuales $^{2}$ para hacer historia con ellas. Es decir, pasar de hacer historia de la fotografía a hacer historia con la fotografía ${ }^{3}$. El cambio de preposición no era baladí: implicaba una mutación historiográfica.

\footnotetext{
1 Una rápida panorámica de dichos estudios realizados en nuestro país puede verse en Fontanella, L. (2007). Los rumbos historiográficos de la fotohistoria de España: pasado, presente y futuro. Revista Latente, 5, pp. 11-26.

${ }^{2}$ Sánchez Vigil, J. M. (2006). El documento fotográfico. Historia, usos, aplicaciones. Gijón: Ediciones Trea.

3 Heras Herrero, B. (2012). El testimonio de las imágenes. Fotografía e Historia. Madrid: Creaciones Vicent Gabrielle. Asimismo, Choma, D. (2009). Do operator ao spectator. Caminhos para una história do tempo presente com fotografias. História Agora, 7. http://www.historiagora.com/dmdocuments/Historia7_artigo_do_operator_ao_spectator. pdf. Tribó Taveira, G. (2005). Enseñar a pensar históricamente. Los archivos y las fuentes documentales en la enseñanza de la Historia. Barcelona: Horsori. Escorza Rodríguez, D. (2008). Fotografía e historia. Un modelo para armar. Elementos básicos para la investigación en fotografía. México: Instituto Nacional de Antropología e Historia. Un interesante trabajo de proyecto fin de máster de Comunicación y Cultura es el de Blanco, M. (2011). El movimiento obrero a través de la fotografía. Universidad de Sevilla (1839-1941). fama2.us.es/fco/tmaster/tmastero5.pdf.
} 


\section{La fotografía como documento histórico. Una propuesta metodológica}

Cualquier rastro del pasado es susceptible de alcanzar la consideración de testimonio histórico, por lo que el concepto de fuente documental se amplía4. Así, las placas fotográficas ofrecen al historiador "una oportunidad inédita e incomparable: la de asistir a la realidad, e incluso a una notable distancia de tiempo, de los acontecimientos que estudia"(Galasso, 2001: 267). Esta potencialidad de la fotografía recibiría la denominación de función de lumbrera:

"Un documento, al ser descriptivo, es una fotografía de un momento dado. La descripción de un paisaje, una ciudad, un personaje nos permite visualizar mentalmente el escenario en el cual se desarrollan los acontecimientos. Obviamente, la irrupción de la fotografía la convierte en una pequeña ventana en la cual podemos asomarnos para observar una realidad que fue y ya no es" (Solano, 2009: 32).

Las fotografías son una forma discursiva de mostrar el mundo visible, son textos visuales (Riego, 2001: 42) que, como tales, han de ser leídos (descifrados) correctamente para escribir historia. Poseen un valor polisémico, siendo el valor documental uno de ellos, porque la fotografía, como elemento transmisor de información (visual) es una fuente histórica, al constituir el documento fotográfico un fragmento congelado de la Historia, y su valor fontal es intrínseco al ser coetánea del hecho del cual da testimonio. La fotografía contiene pistas que permiten una mejor comprensión de la realidad estudiada, pues una fotografía es siempre una huella de la realidad (Guran, 1999: 142). Sin embargo, esta última aseveración puede ser matizada, pues hay quien piensa que la fotografía "no es una duplicación fiel de la percepción humana, sino una representación recreada" (Gubern, 1997: 36).

4 La fotografía, en el terreno documentalista y archivístico, ha alcanzado una plena valoración como fuente documental, como puede verse, por ejemplo, en Astudillo Rojas, C. (2010). Catalogación de documentos patrimoniales históricos y etnográficos. Valparaíso: Pontificia Universidad Católica de Valparaíso. 
Por supuesto, las fotografías, al igual que otras fuentes documentales (escritas, orales, materiales, sonoras, etc.) tienen un margen de subjetividad que ha de tener en consideración el historiador: carga ideológica del fotógrafo (en el tema elegido), la posible manipulación de la foto para ofrecer una determinada visión de la realidad, el encuadre, la técnica empleada, etc. Las fotografías son documentos históricos cargados de la opinión de su respectivo autor, por lo que será el investigador quien, al decodificarla, determine en última instancia la fiabilidad documental de la fotografía para el trabajo que pretende realizar. Una fotografía, por consiguiente, no es un documento aséptico para el historiador, por lo que debe aproximarse a ella con la misma prevención que hacia el resto de fuentes documentales, lo cual no es óbice para que, con todo, sea considerada "uno de los documentos más objetivos que existen, aunque su utilización como fuente fidedigna sea relativamente próxima en el tiempo" (Sánchez Vigil, 1999: 38).

Lo que sucede es que, al igual que la criba y crítica de las fuentes históricas tradicionales es algo realizado desde hace decenios por los historiadores porque reciben formación universitaria para ello, no existe tradición académica en un cribado y crítica de los documentos fotográficos, lo que produce problemas al interpretarlos que se solventan por la experiencia y el continuo aprendizaje y reciclaje del investigador.

Por todo ello, para historiar con fotografías es necesario disponer de una metodología: habrá que reunir una serie de ellas con un nexo común temático, desmenuzar la información aportada visualmente, reflexionar sobre cada documento y elaborar un discurso histórico en el que la fotografía sea la fuente primaria, ayudándose de otras fuentes secundarias tales como: documentación escrita de toda clase, testimonios orales, otras fuentes iconográficas, etc. 5 La idea que subyace es que no se debe considerar el

5 Una teoría y metodología para escribir historia con fotografías puede verse en Lara López, E. L. La fotografía como documento histórico-artístico y etnográfico: una epistemología (2005). Revista de Antropología Experimental, 5, texto 10. http://www.ujaen.es/huesped/rae/articulos2005/lara2005.pdf. Asimismo, Lara López, E. L. (2004). La religiosidad popular pasionista contemporánea (Jaén, 1859-1978): una historia a través de la fotografía como fuente documental. Instituto de Estudios 
documento visual de forma aislada, porque forma parte de un fenómeno de comunicación global. Las fotografías nos revelan información y emoción, son un reflejo de existencias y ocurrencias que nos permiten acceder al conocimiento de una época suministrándonos información (codificada visualmente) de la época y el lugar en los que fueron tomadas.

Este corpus de imágenes no sólo es un banco documental para el investigador, sino que, de alguna manera, potencia su capacidad de narración histórica, porque:

"A partir de la fotografía podemos generar un tiempo de narración recurrente como realizamos con nuestros recuerdos, que en principio se mantienen aislados, como instantes fotográficos, y que después seleccionaremos para conectar unos con otros en un determinado momento y elaborar una narración más extensa" (Pantoja, 2007: 189).

La digitalización de imágenes facilitará mucho la tarea de trabajar con soportes materiales dispares, evitando el manipulado de documentos frágiles como los daguerrotipos, promoviendo el préstamo de las imágenes procedentes de colecciones particulares cuyos propietarios pueden mostrarse reticentes a la cesión temporal para su estudio, y también, el formato digital posibilita mejorar el visionado de documentos de mala calidad (prensa gráfica de finales del s. XIX y comienzos del XX) o deteriorados por el paso del tiempo.

Una vez realizada la serie temática hay que consignar una serie de datos de cada fotografía: datarla cronológicamente con la mayor precisión posible, intentar conocer su autor, tecnología utilizada, y lugar donde se tomó.

Como todas las fuentes, la fotografía es interpretable, hay que contextualizarla cronológica y temáticamente para leer adecuadamente la información que contiene. Aunque partimos de la base de que constituye un fragmento detenido de la realidad (del pasado efímero), por sí sola es algo inconexo si no se organiza una seriación fotográfica temática, es decir, debe 
organizarse una cadena de imágenes referidas a un mismo fenómeno para que dicha información no queden deslavazada, inconclusa, sino cohesionada. Hay que tener una sólida formación fotohistórica para desmenuzar los códigos visuales y los estereotipos de las fotografías, sobre todo las del s. XIX y principios del s. XX: conocimiento de las técnicas (daguerrotipo, colodión, tarjeta de visita...), posible identificación del operador fotográfico, retratos realizados en gabinetes, placas de vistas de ciudades tomadas con finalidad propagandística o turística, instantáneas de fotógrafos profesionales o aficionados, postales, imágenes de clara vocación documental, etc. La carencia de conocimientos de historia de la fotografía llevaría al investigador a realizar lecturas equivocadas de los documentos visuales y a invalidar su trabajo.

El conocimiento de la fotohistoria permite conocer y relacionar las claves interpretativas de cada fotografía, pues muchos de los retratos de estudio decimonónicos, por ejemplo, buscaban la identificación con el mundo burgués, de manera que los convencionalismos sociales prevalecían sobre los caracteres individuales. Así, los decorados de los gabinetes (forillos, mobiliario, atrezo, etc.) reconstruían interiores domésticos de la mediana y alta burguesía, o se retrataba a los difuntos (sobremanera los niños) como si estuviesen dormidos en mecedoras, cunas o camas, rodeados de sus hermanos o padres, para tener una imagen amable del muerto, que aparentaba descansar, y eso para al menos tener en un álbum una imagen de esa persona, pues si no se disponía de una fotografía de ella, el tiempo haría las veces de decapante y borraría de la memoria familiar los rasgos físicos que tuvo.

¿Y qué fotografías son las más valiosas a priori como documento histórico? Pensamos que las que pertenecen al denominado documentalismo gráfico, nacido en las postrimerías del s. XIX y en auge a partir de la Primera Guerra Mundial, pues los avances tecnológicos posibilitaron la reducción del tamaño de las máquinas y su equipo y el profesional podía moverse con facilidad para documentar visualmente la realidad que él observaba y que le interesaba 
plasmar. El documentalismo gráfico fue practicado por fotógrafos aficionados y por profesionales (por motivos etnográficos, turísticos o sociales) para aprehender la realidad, para presentar una escena capaz de narrar por sí misma un hecho. Estas imágenes fotográficas atesoran una riquísima información para el historiador.

El historiador, al analizar documentos fotográficos, debe renunciar a la tentación de practicar un presentismo del pasado histórico narrado visualmente, ya que una fotografía es un producto técnico producido en un determinado periodo de la historia que responde a unos códigos culturales que la hacen legible (entendible) a todos quienes la contemplan, que ven en dicha foto un recordatorio visual de tiempos pretéritos y una fuente documental en la actualidad. Es decir, las imágenes deben situarse en su propia tradición cultural, con sus convenciones y códigos de representación ${ }^{6}$. El desconocimiento de esto genera una interpretación sesgada de tales documentos.

Las imágenes fotográficas, en suma: a) son documentos históricos autónomos equiparados en importancia al resto de fuentes tradicionales; b) han de ser debidamente contextualizadas por medio de su cotejo con fotos de la misma temática desde una doble perspectiva sincrónica y diacrónica; c) nos surten de un ingente caudal informativo social, cultural, político y material; d) poseen una naturaleza polisémica que el historiador-antropólogo ha de saber discernir. La fotografía, por consiguiente, es un soporte para la memoria, un dispositivo para atesorar recuerdos7.

Pero los documentos fotográficos poseen, además, una notable capacidad evocativa: nos provocan la sensación de que el pasado parezca estar presente, son una especie de ventana abierta para que viajemos en el tiempo y asistamos, como privilegiados espectadores, a episodios ocurridos años atrás,

\footnotetext{
${ }^{6}$ Una obra pionera en nuestro país y capital para historiar con imágenes es Riego, B. (2001). La construcción social de la realidad a través de la fotografía y el grabado informativo en la España del siglo XIX. Santander: Universidad de Cantabria.

7 Devoto, E. A. (2013). La imagen como documento histórico-didáctico: algunas reflexiones a partir de la fotografía. Revista de Educación, 6, pp. 73-94.
} 
cancelados cronológicamente. Ofrecen al investigador "una oportunidad inédita e incomparable: la de asistir en realidad, e incluso a una notable distancia de tiempo, a los acontecimientos que estudia"(Galasso, 2001: 267). Las fotografías incluso han podido modificar nuestro sentido del conocimiento histórico al producir lo que Roland Barthes denominaba el efecto realidad: las placas antiguas nos permiten revivir lo que sucedió. Y si continuamos esta línea de razonamiento, terminaríamos aseverando que las fotografías no son un testimonio de la historia, sino que en sí mismas son algo histórico.

Peter Burke, profesor de Cambridge y uno de los grandes renovadores de la historia cultural, planteó que los historiadores deberían prestar atención al cine al construir sus narrativas históricas incorporando en sus obras las escenas retrospectivas, los montajes paralelos y la alternancia de escena y relato para relacionar los acontecimientos y las estructuras y así presentar puntos de vista múltiples (Burke, 1999: 304-305).

Recojamos el guante lanzado por Burke y planteemos la posibilidad de que el historiador, al pretender plasmar la narración visual de las fotografías analizadas, recurra en su escritura a la técnica del montaje cinematográfico, y ello en base a las hibridaciones discursivas: el cruce o mestizaje conceptual y narrativo que atraviesa todas las formas de comunicación actuales (Marzal, Martín y Soler, 2011).

¿Y qué elementos podría tener ese tipo de escritura histórica?: una estructura cronológica no lineal para enfatizar determinados aspectos, modular la tensión narrativa y promover el interés del lector; el uso de la microhistoria para mostrar aspectos de la vida de la gente poco importante (sería el equivalente cinematográfico de personajes secundarios o extras), y asimismo incardinar la microhistoria en una historia más amplia, donde tengan cabida personajes de mayor rango; recurrir a la historia de las mentalidades para mostrar la vida cotidiana, sin desdeñar la descripción de acontecimientos capitales que ocurrieran en el periodo estudiado; entrecruzar distintas historias (aparentemente desconectadas entre sí) hasta que desemboquen en 
una historia conjunta; narrar la historia a través de diferentes personajes o desde la óptica de distintos grupos sociales, mostrando variados puntos de vista sobre un mismo fenómeno histórico; y usar el flash back (retroceso a un punto anterior al que se relata) y la simultaneidad de acciones.

El inequívoco poder evocativo de las fotografías puede permitirle al investigador construir una historia así, pues en lo concerniente a una parte significativa del s. XX, dichos trabajos, encajados en el marco cronológico de la Historia del Tiempo Presente, tendrían la virtualidad de constituir una historia vivida para muchas personas, que o bien vivieron los acontecimientos relatados y los reviven a la luz de la ciencia histórica, o bien los viven de una manera retrospectiva. Y ello en base a la potencialidad de las fotografías como elemento constructor de la memoria y de la identidad, pues nos ayudan a elaborar un relato de nuestras vidas y a formarnos una idea de colectividad.

El historiador que se lance a escribir una historia de este tipo deberá interiorizar la técnica del montaje cinematográfico, y atreverse a ser el guionista, el montador y el director de una obra basada en la fotografía como fuente documental. Se construiría así una nueva forma de expresión historiográfica.

La empresa no es fácil, pero sí sugestiva.

\section{La necesidad de la formación multidisciplinar del historiador}

Para poder interpretar y leer correctamente documentos fotográficos, el historiador debe acumular una panoplia de conocimientos sobre la época que estudia, pero no revueltos (en una suerte de gazpacho teórico-metodológico), sino debidamente procesados y sedimentados. Para ello es imprescindible que se desenvuelva con soltura en historia social, política y económica y que integre dichos saberes en la historia de las mentalidades, que, a nuestro juicio, es la corriente historiográfica más adecuada para el campo que nos atañe, entendiendo como tal historia el conjunto de instrumentos mentales 
del que disponen los hombres de una época determinada ${ }^{8}$. Pero la mayoría de las hornadas de historiadores egresados de las universidades hispanas no reciben una correcta formación documental fotográfica. Las razones son varias9.

El peso de la historia de la fotografía como disciplina académica sigue recayendo en los estudios de Historia del Arte, y de manera secundaria en los de Ciencias de la Comunicación, aunque los archiveros y documentalistas cada vez reciben mejor formación en este sentido por la necesidad de incorporar, catalogar y custodiar fotografías (desde los daguerrotipos en adelante) en fondos documentales específicos según criterios científicos ${ }^{10}$, por su consideración de bien patrimonial inmaterial. Ahora bien, el alumnado de los grados de Historia o de Humanidades todavía no tiene la oportunidad durante la carrera de familiarizarse con técnicas y herramientas conceptuales para historiar con imágenes fotográficas.

Así esos historiadores deben suplir sus carencias metodológicas a través de cursos de posgrado (un máster, el curso de algún programa de doctorado, jornadas y encuentros, universidades de verano...), o en todo caso a través de las clases de experimentados profesores que sí se han preocupado por los documentos fotográficos. O bien, los jóvenes historiadores han de procurarse una formación autodidacta buscando literatura científica (en papel y en la red), que afortunadamente, cada vez hay de mejor calidad, fruto del esfuerzo continuado de muchos investigadores.

El modelo a seguir, en nuestra opinión, sería el de las universidades anglosajonas, pues en sus cultural studies, los estudiantes salen de las aulas

\footnotetext{
8 González Lopo, D. L. (2002). Historia de las mentalidades. Evolución histórica de un concepto complejo y polémico. Obradoiro de Historia Moderna, 11, pp. 135-190.

9 Siguen siendo válidos los postulados defendidos por Riego, B. (1996). La historiografía española y los debates sobre la Fotografía como fuente histórica. Ayer, 24, pp. 91-111.

10 Pavao, L. (2001). Conservación de colecciones de fotografía. Instituto Andaluz de Patrimonio Histórico, centro Andaluz de Fotografía: Sevilla. Ancona López, A. P. (2011). Contextualización archivística de documentos fotográficos. Alexandria, 8, pp. 3-16. Un estado de la cuestión lo encontramos en Mulet $\mathrm{M}^{\mathrm{a}}-\mathrm{J}$. (2007). El acceso a la información sobre el patrimonio fotográfico en el Estado español. Revista Latente, 5, pp. 57-72.
} 
con una formación transdisciplinar ${ }^{11}$ necesaria para historiar con imágenes. Un modelo alternativo sería que el historiador español adquiriese conocimientos de antropología visual para complementar su capacidad de lectura fotográfica.

\section{Los documentos fotográficos y las duraciones temporales}

En 1958, Fernand Braudel, historiador francés de la Escuela de Anales, escribió un artículo que establecía una tipología de duraciones en base a diversas realidades históricas ${ }^{12}$. En esencia, Braudel hablaba de una triple división del tiempo histórico: tiempo corto, medio y largo.

El tiempo corto correspondía al de la vida cotidiana "el de nuestras ilusiones, el de nuestras rápidas tomas de conciencia, el tiempo por excelencia del cronista, del periodista", y tendría una incidencia "individualizante" al referirse a los acontecimientos. Este tiempo corto o de los acontecimientos era denostado por Braudel al estimar que "no constituye toda la realidad, todo el espesor de la Historia sobre el que la reflexión científica pueda trabajar a sus anchas”, de forma que "el tiempo corto es la más caprichosa, la más engañosa de las duraciones” (Braudel, 1968).

Sin embargo, este desdén por el acontecimiento sería corregido posteriormente por Pelai Pagès al pensar que:

"El acontecimiento, cuya protección ha sido posible merced a la importancia cada vez mayor de los medios de comunicación y del mundo de la imagen, sólo sería históricamente inteligible en relación con la sociedad que lo produce, y sólo así se explicaría la inmediata historización del acontecimiento" (Pagès, 1988: 245).

Esta afortunada expresión, la historización del acontecimiento, sería lo que hacen las fotografías en tanto en cuanto documentos visuales: capturar el

${ }^{11}$ Una síntesis de la necesidad de que el historiador tenga una formación interdisciplinar puede verse en Burke, P. (2010). Hibridismo cultural. Reflexiones sobre teoría e historia. Madrid: Akal.

12 Braudel, F. (1958). La longue durée, Annales, E. S. C., 13, pp. 725-753. 
instante, congelar el momento. Por consiguiente, el investigador puede historiar con imágenes, construir un discurso científico incardinado en la microhistoria, entendiendo por tal la reducción de la escala de observación, el análisis microscópico y el estudio intensivo del material documental ${ }^{13}$.

El tiempo medio (según Braudel) sería el de la coyuntura, que Pierre Vilar define como "el conjunto de condiciones articuladas entre sí que caracterizan un momento en el movimiento global de la materia histórica" (Vilar, 1980: 81). Esta duración intermedia es la idónea para acometer una investigación histórica con fotografías, pues permite acotar periodos y -dentro de éstoselegir algún tema. Por ejemplo: en fotos pertenecientes a la Primera Guerra Mundial (1914-1918), analizar la vida de los soldados en las trincheras, la incorporación de la mujer al mundo del trabajo, los movimientos sufragistas, la sociabilidad en casinos de artesanos y tabernas, etc.

El tiempo largo o de larga duración se correspondería con el de las estructuras: "para nosotros, los historiadores, una estructura es indudablemente un ensamblaje, una arquitectura, una realidad que el tiempo tarda enormemente en desgastar y en transportar” (Braudel, 1968: 70). El investigador visual podrá utilizar documentos fotográficos a partir de 1839, lo que le permite analizar diacrónicamente numerosas imágenes de muchas temáticas y extraer conclusiones en el relato histórico construido con fotografías. Las imágenes fotográficas permiten reconstruir escenarios sociales de un periodo concreto y nos permiten visualizar las transformaciones experimentadas a lo largo del tiempo.

Los documentos visuales engloban por tanto las duraciones temporales, y en ellos se pueden estudiar elementos sociales, culturales, emotivos (los sentimientos, la sensibilidad, los prejuicios), el imaginario (como constructo cultural de una época) y el inconsciente (los miedos colectivos). Lo que ha venido a revalorizar los estudios de la historia de las mentalidades, y ello

\footnotetext{
13 Serna, J. y Pons A. (2000). Cómo se escribe la microhistoria. Ediciones Cátedra: Madrid. También Man, R. (2013). La microhistoria como referente teórico-metodológico. Un recorrido por sus vertientes y debates conceptuales. Historia Actual Online, 30, pp. 167-173.
} 
porque para estudiar las supervivencias del pasado en el presente es imprescindible conocer las costumbres, las tradiciones, la vida cotidiana y el pensamiento colectivo a través de las duraciones temporales.

Los documentos fotográficos -en mayor medida que otros- constituyen un verdadero filón histórico, al tener como protagonistas a segmentos poblacionales tradicionalmente olvidados por las fuentes tradicionales.

\section{La historia de los deshistoriados}

Tras la Segunda Guerra Mundial, los historiadores ingleses y estadounidenses se replantearon las perspectivas y enfoques de construcción de los procesos históricos, de modo que desarrollaron una nueva corriente historiográfica, la historia social, y estudiaron la vida cotidiana del hombre corriente (como una derivación de la historia de las mentalidades). Nació la historia desde abajo.

Esta novedosa y pujante manera de hacer historia se contraponía a la tradicional importancia que había tenido la historia política y económica centrada en las elites, en los actores principales de los sucesos, donde el hombre común no tenía cabida. Era a través de los generales, de los ministros y de los reyes (de la documentación generada por ellos y sobre ellos) como se construían los relatos históricos; mientras los soldados rasos, las personas corrientes, no eran sino meras comparsas (cifras, seres anónimos, masas) en dicha manera de historiar. En definitiva: no contaban para nada.

Es más, en las décadas de 1950 y 1960 hubo un abuso historiográfico de una historia social y económica despojada de personas, donde se priorizaba a las estructuras, presentadas como entidades motoras de los cambios históricos en los que los sujetos prácticamente no tenían importancia, pues lo fundamental era describir las grandes tendencias macroeconómicas (trufadas de estadísticas, de análisis cliométricos), los movimientos sociales en los que, paradójicamente, las personas (a escala individual) jamás aparecían 
reflejadas. El hartazgo de esta manera de escribir historia fue de abajo a arriba: primero se rebelaron los estudiantes universitarios, hastiados de tener que aprender una historia deshumanizada (como sustituta de una historia de las elites), mecanicista, compuesta por estructuras que chocaban entre sí como placas tectónicas; más tarde los profesores comenzaron a construir modelos teóricos alternativos y a escribir en base a nuevas corrientes historiográficas que tuvieron su apogeo en los años setenta y ochenta del siglo pasado.

Esta corriente historiográfica de la historia desde abajo planteaba tener en cuenta tres criterios básicos: incorporar nuevos sujetos a la hora de reconstruir el pasado, trascender la esfera de la política, y por último incorporar nuevas fuentes documentales y tomar préstamos conceptuales y metodológicos de otras disciplinas de las ciencias sociales. De esta forma, y merced al paraguas de la historia de las mentalidades, entran en el foco histórico las masas, las clases sociales y la cultura popular.

La historia desde abajo aporta distintas perspectivas para reconstruir la realidad histórica dentro del marco de la vida cotidiana, eliminando la elitista distinción de individuos -o grupo- relevantes o insignificantes. Y para desenvolverse con facilidad por la vida cotidiana de las poblaciones en la Edad Contemporánea, será imprescindible manejarse con soltura en la historia cultural, una variante historiográfica en la que las universidades inglesas serán la punta de lanza ${ }^{14}$.

Una línea de investigación dentro de esta corriente sería la historia cultural de las emociones (Burke, 2005), en la que las fotografías brindarían una excelente posibilidad para sondear los estados de ánimo colectivos en el marco de: mítines, manifestaciones, algaradas, desfiles patrióticos, levantamientos armados, exiliados, damnificados por catástrofes naturales o bélicas, etc. La historia cultural de las emociones es aún más una novedosa

14 Un ejemplo es el de Burke, P. (2006). Formas de historia cultural. Madrid: Alianza Editorial. También, Serna, J. y Pons, A. (2005). La historia cultural. Autores, obras, lugares. Barcelona: Akal. 
propuesta que una tendencia historiográfica, de manera que quienes la han abordado han empleado fuentes tradicionales: memorias, diarios, epístolas, prensa escrita, etc., pero no imágenes fotográficas como las antedichas, por lo que nos limitamos a sugerir su utilización.

Hacer historia desde abajo exigía al investigador ser creativo en el sentido de explorar nuevas fuentes documentales, por lo que la historia oral (tomada de la ciencia antropológica) entró de lleno en el catálogo de recursos, así como el exhaustivo rastreo de la prensa y revistas gráficas (éstas últimas surgidas en la segunda mitad del s. XIX), o el análisis de cartas y diarios. La tarjeta postal ilustrada será asimismo una buena fuente histórica, aunque su utilización apenas haya suscitado interés en nuestro país, salvo contadas excepciones ${ }^{15}$.

La tarjeta postal ilustrada, y sobre todo la fotográfica, ofrecerá un recorrido visual por lugares exóticos, pintorescos, alejados de los circuitos culturales europeos. O simplemente, dichas tarjetas reproducían enclaves turísticos y paisajes que heredaban, de alguna manera, la práctica del Grand Tour reformulada en el naciente turismo burgués de comienzos del s. $\mathrm{XX}^{16}$.

Las tarjetas postales (enviadas con afán turístico) serán los primeros documentos visuales en introducir personajes secundarios como telón de fondo, e incluso como protagonistas: miembros de tribus africanas, hombres y mujeres de pueblos del Oriente Próximo o del Magreb. En paralelo, la fotografía documentalista o etnográfica centrará su atención en dichas personas, lo que ayudará a consolidar en Occidente un poderoso imaginario

${ }^{15}$ A este respecto es fundamental acudir a Riego, B. (2011). Una revisión del valor cultural de la tarjeta postal ilustrada en el tiempo de las redes sociales. Fotocinema, 2, pp. 3-18, y también Riego, B. (ed.) (2011). España en la tarjeta postal. Un siglo de imágenes. Barcelona: Lunwerg Editores. Palenque, M. (2013). Poesía, fotografía y tarjetas postales: Campoamor, Kaulak y Lázaro en la Serie M de la Colección Cánovas. Catálogo de la exposición Correspondencia sin privacidad: billetes, tarjetas postales y epístolas literarias en la Colección Lázaro Galdiano, pp. 85-103. Madrid: Fundación Lázaro Galdiano. López Hurtado, M. (2013). La tarjeta postal en España: usos y tendencias. Revista General de Información y Documentación, vol. 23, pp. 437-453.

${ }^{16}$ La carrera colonial iniciada a mediados del s. XIX puso de moda el orientalismo en el mundo occidental. La tarjeta postal ilustrada y las fotografías de temática orientalista tuvieron una gran difusión en Europa y América, popularizándose el imaginario orientalista entre la burguesía, como queda patente en Martínez Hernández, $M^{a}$. J. (2005). Fuentes visuales para la Historia Contemporánea y del Arte. El orientalismo en Jaén (1897-1920). Boletín del Instituto de Estudios Giennenses, 190, pp. 387-420. 
orientalista que tardará mucho tiempo en desvanecerse, pues se retroalimentará con dichas fotos, con una copiosa literatura de viajes, con corrientes artísticas pujantes y con una filmografía de éxito.

Las fotografías que realizaron los operadores profesionales que trabajaron en España en las décadas de 1850 y 1860 plasmaron una amplia variedad de tipos populares. Así, quedaron numerosos registros visuales de personas del pueblo llano que contienen un caudal informativo excepcional para el historiador ${ }^{17}$. Los estratos sociales humildes fotografiados permiten escribir no sólo una historia desde abajo, sino también una historia de los deshistoriados, pues las placas fotográficas reproducen formas de vida y profesiones de hombres y mujeres de los que las fuentes documentales tradicionales apenas se ocupaban. Son numerosos los ejemplos que se pueden poner: vida cotidiana de minorías étnicas, ambientes domésticos de las clases empobrecidas, condiciones laborales de obreros en sus centros de trabajo o de artesanos en sus talleres y obradores, emigrantes (embarcando, en los apeaderos de las estaciones de tren o de autobús, o bien en los barracones o infraviviendas en algunos de los países donde se asentaban), manifestaciones de religiosidad popular y de formas de sociabilidad (tabernas, cafés, círculos católicos y hermandades obreras), etc.

La historia de los deshistoriados se interesaría por la existencia y las conductas de aquellos a quienes las fuentes históricas tradicionales han olvidado o convertido en una parte irrelevante de una masa. Por eso hacemos hincapié en una narración histórica a través de documentos visuales que plasmen la vida cotidiana de las personas y de la cultura como código que regula sus actuaciones.

${ }_{17}$ Los fotógrafos Charles Clifford y Jean Laurent serían los paradigmas en este sentido. Existen variados estudios sobre estos pioneros fotográficos en España, sirvan como botón de muestra el de Martos Causapé, J. F. (2005). Del daguerrotipo al colodión. España a través de la fotografía del s. XIX. Berceo, 149, pp. 9-34, y el de Vega, J. (2013). Del espectáculo de la ciencia a la práctica artística cortesana: apuntes sobre la fortuna de la fotografía en España. Revista de Dialectología y Tradiciones Populares, vol. XLVIII, pp. 359-383. 


\section{Historia y Antropología: convergencias}

Lejos de ser compartimentos estancos, las disciplinas de Historia y Antropología, pueden trasvasarse (por vasos comunicantes) elementos conceptuales, estrategias de indagación y utillaje metodológico que las enriquezca mutuamente. No cabe duda de que la antropología visual es un venero para los historiadores que trabajan con documentos fotográficos.

El antropólogo norteamericano Clifford Geertz fue pionero en establecer las conexiones entre historiadores y etnógrafos en sus respectivas investigaciones ${ }^{18}$, lo que conduciría a unas interrelaciones en base, sobre todo, al concepto de narración densa: la interpretación de una cultura mediante la descripción precisa y concreta de determinadas prácticas y sucesos. Y para la descripción densa no existiría mejor técnica que la micronarración: la exposición de un relato sobre gente corriente en un escenario local ${ }^{19}$. Las fotografías serían unos formidables documentos para esta técnica histórica. Pero para que el uso de documentos visuales sea útil, hay que construir una micronarrativa de acontecimientos en un escenario local contextualizándolos en un marco espacial superior. Es decir, la investigación microhistórica hay que insertarla en la historia global, en lo macrosocial. De esta forma se trasciende el localismo, tan estéril y corto de miras, como sucede en voluntariosas investigaciones históricas, que se agotan en sí mismas por no injertarse en el tronco de una historia más amplia.

La fotografía es una de las herramientas básicas de la antropología visual, sobre todo la de tipo documentalista, pues en ella se prioriza la captación de un ambiente social en lugar de la valía artística que quiera imprimirle el fotógrafo, aunque el valor documental o etnográfico y el valor artístico no son excluyentes.

18 Geertz, C. (2002). Reflexiones antropológicas sobre temas filosóficos. Barcelona: Paidós. 19 La micronarración nacería del concepto de microhistoria, como desarrolla Burke P. (1999). Historia de los acontecimientos y renacimiento de la narración, en Burke, P. (ed.) Formas de hacer historia. Madrid: Alianza Editorial, p. 299. 
La antropología visual investiga la cultura como un sistema ordenado de comunicación humana, de manera que analiza los usos sociales de la imagen como un producto elaborado por el hombre y, al mismo tiempo, realiza fotografías como parte del discurso antropológico (como fuente del conocimiento). Esta especialidad antropológica parte de la creencia de que la cultura se manifiesta en los símbolos visibles, en las ceremonias, en los rituales y en los objetos de la vida cotidiana, situados en escenarios construidos por el hombre o en espacios naturales. Hace hincapié en que las fotografías son objetos capaces de construir una memoria e identidad colectivas, lo que les otorga un estatus por derecho propio dentro de la cultura material: activan los recuerdos, evocan sucesos pretéritos, vinculan el pasado con lo actual, algo que se explicita, por ejemplo, en las manifestaciones de cultura popular20. Y además, los documentos fotográficos perpetúan el instante con gran capacidad descriptiva. Todo esto repercutiría en lo que podría denominarse un giro visual en los estudios históricos.

\section{Conclusiones}

Una vez asumida la superación de la fotohistoria, los historiadores interesados en los documentos visuales están de acuerdo en que el siguiente paso es construir una narración histórica con fotografías. Sin embargo, la gavilla de estudios publicados sobre ello suelen aportar conceptos teóricos y estrategias metodológicas sin adjuntar ejemplos prácticos de cómo historiar con fotos. O a lo sumo, ofrecen algunos ejemplos individuales: cómo interpretar históricamente determinados documentos visuales. Este esfuerzo investigador es loable, y en muchos casos está muy bien fundamentado, sin embargo, los historiadores, salvo honrosas excepciones, siguen apegados a las fuentes documentales tradicionales, y ello a pesar de vivir en un mundo plagado de imágenes.

\footnotetext{
${ }^{20}$ Velasco, $M^{\mathrm{a}}$. J. (2011). La fotografía de la cultura popular a partir de la Transición española. Fotocinema, 2, pp. 56-74.
} 
La proliferación de centros de investigación y de universidades en España en las tres últimas décadas, la renovación de los planes de estudio, la normalización de la historiografía española respecto a la de otros países occidentales, el acceso a las investigaciones extranjeras a través de Internet y de otros conductos, la asistencia de profesores a congresos internacionales y el recambio generacional en los departamentos universitarios, ya no permite achacar a la provecta edad profesoral el desinterés hacia las fuentes documentales fotográficas.

La razón fundamental estriba, a nuestro entender, en la dificultad que entraña historiar con fotografías, porque el investigador ha de dominar no sólo la fotohistoria, sino desenvolverse con soltura en diferentes corrientes historiográficas, e incluso disponer de conocimientos antropológicos. Y esto, para una persona sola, supone un enorme esfuerzo. Además, hay que terminar de construir una hermenéutica histórica de los datos que aportan los documentos visuales.

Para salvar ese escollo, habría varias soluciones: la formación de grupos de investigación mixtos de historiadores y antropólogos; enfatizar la consideración de la fotografía como documento histórico en lugar de verla como un recurso didáctico o mero un apoyo al texto; la inserción en manuales de técnicas de investigación históricas de una teoría y metodología para historiar con imágenes fotográficas que constituyan capítulos específicos, no una rápida mención; la creación de asignaturas (o cátedras) de Historia y Documentos Visuales; o que el historiador solicitase la colaboración de diversos especialistas historiográficos para que visionasen las series fotográficas, leyesen el trabajo realizado y aportasen sugerencias a través de intercambios de pareceres.

Creemos que lo esencial no es que el historiador se sature de información mediante una acumulación de fotografías que desplacen en importancia a las fuentes tradicionales, sino darle un giro visual a la historia, tomar conciencia de que una reinterpretación visual del pasado puede modificar nuestra visión histórica. 
Una vez pertrechados con un adecuado utillaje conceptual, teórico y metodológico, no cabe sino demostrar con ejemplos palmarios que historiar con fotografías no es una curiosa o exótica tentativa, meros fuegos de artificio (espectaculares pero efímeros), sino una tendencia historiográfica consolidada.

\section{Referencias bibliográficas}

Alted Vigil, A. y Sánchez Belén, J. A. (2005). Métodos y técnicas de investigación en historia moderna e historia contemporánea. Madrid: Centro de Estudios Ramón Areces.

Ancona López, A. P. (2011). Contextualización archivística de documentos fotográficos. Alexandria, 8, pp. 3-16.

Aróstegui, J. (2004). La Historia vivida. Sobre la Historia del Presente. Madrid: Alianza Editorial.

Astudillo Rojas, C. (2010). Catalogación de documentos patrimoniales históricos y etnográficos. Valparaíso: Pontificia Universidad Católica de Valparaíso.

Baeta Neves, L. V. (2004): A fotografia como documento histórico. Em Tempo de Histórias, 8, pp. 1-11.

Barthes, R. (1989). La cámara lúcida. Notas sobre la fotografía. Barcelona: Paidós.

Berger, J. y Mohr, J. (2007). Otra manera de contar. Gustavo Gili: Barcelona.

Blanco, M. (2011). El movimiento obrero a través de la fotografía. Universidad de Sevilla (1839-1941). http://www.fama2.us.es/fco/tmaster/tmastero5.pdf.

Braudel, F. (1968). La historia y las ciencias sociales. Madrid: Alianza Editorial.

Burke, P. (1999). Formas de hacer historia. Madrid: Alianza Editorial.

Burke, P. (2001). Visto y no visto. El uso de la imagen como documento histórico. Barcelona: Crítica.

Burke, P. (2005) Is There a Cultural History of the Emotions? En Gouk, Penelope y Hills, Helen (eds.) Representing Emotions: New Connections in the Histories of Art, Music and Medicine, Aldershot, Ashgate, pp. 35-48.

Burke, P. (2006). Formas de historia cultural. Madrid: Alianza Editorial.

Burke, P. (2008). Cómo interrogar a los testimonios visuales. En Palos i Peñarroya, J. L. y Carrió Invernizzi, D. (coords.) La historia 
imaginada: construcciones visuales del pasado en la Época Moderna. Madrid: Centro de Estudios Europa Hispánica, pp. 29-40.

Burke, P. (2010). Hibridismo cultural. Reflexiones sobre teoría e historia. Madrid: Akal.

Cabeza, J. y Rodríguez, A. (coords.) (2004). Creando cine, creando historia. La representación cinematográfica de ideas y movimientos sociales. Madrid: Universidad Complutense.

Ceballos Hornero A. y Ceballos Hornero A. (2006). Categorías de tiempo histórico. Éndoxa: Series filosóficas, 21, pp. 137-156.

Choma, D. (2009). Do operator ao spectator. Caminhos para una história do tempo presente com fotografias. História Agora, 7. http://www.historiagora.com/dmdocuments/Historia7_artigo_do_o perator_ao_spectator.pdf.

De Miguel, J. y Pinto, C. (2003). Sociología visual. Madrid: CIS.

Devoto, E. A. (2013). La imagen como documento histórico-didáctico: algunas reflexiones a partir de la fotografía. Revista de Educación, 6, pp. 73-94.

Díaz Barrado, M. P. (2004). Imágenes para la memoria. La fotografía en soporte digital. Pasado y Memoria. Revista de Historia Contemporánea, 3, pp. 57-72.

Díaz Barrado, M. (2012). La imagen en el tiempo. El uso de las fuentes visuales en la Historia. Historia Actual Online, 29, pp. 141-162.

Enríquez Solano, F. (2009). El documento como fuente para estudios científicos culturales. Criterios de valoración. Memoria XXI Congreso Archivístico Nacional de Costa Rica, pp. 29-35.

Escorza Rodríguez, D. (2008). Fotografía e historia. Un modelo para armar. Elementos básicos para la investigación en fotografía. México: Instituto Nacional de Antropología e Historia.

Febrero Fernández, N. (2013). Aproximaciones teóricas en antropología visual: fundamentos metodológicos. Estudios sobre el Mensaje Periodístico, 19, pp. 725-734.

Ferro, M. (2008). El cine, una visión de la Historia. Madrid: Akal.

Fontanella, L. (2007). Los rumbos historiográficos de la fotohistoria de España: pasado, presente y futuro. Revista Latente, 5, pp. 11-26.

Freund, G. (2011). La fotografía como documento social. Barcelona: Gustavo Gili.

Gaddis, J. L. (2004). El paisaje de la historia. Cómo los historiadores representan el pasado. Barcelona: Anagrama.

Galasso, G. (2001). Nada más que historia. Teoría y metodología. Barcelona: Ariel.

Geertz, C. (2002). Reflexiones antropológicas sobre temas filosóficos. Barcelona: Paidós. 
González Lopo, D. L. (2002). Historia de las mentalidades. Evolución histórica de un concepto complejo y polémico. Obradoiro de Historia Moderna (11), pp. 135-190.

Gubern, R. (1997). Medios icónicos de masas. Madrid: Historia 16.

Guran, M. (1999). Mirar/ver/comprender/contar/ la fotografía y las Ciencias Sociales. Segunda Muestra Internacional de Cine, Vídeo y Fotografía. El Mediterráneo, imagen y reflexión. Working Papers, 3, pp. 139-141.

Hernández Sandoica, E. (2004). Tendencias historiográficas actuales. Escribir historia hoy. Madrid: Akal.

Hernández, F. (2005). ¿De qué hablamos cuando hablamos de cultura visual? Educaçao \& Realidade, 30, pp. 9-34.

Heras Herrero, B. (2012). El testimonio de las imágenes. Fotografia e Historia. Madrid: Creaciones Vicent Gabrielle.

Laborda, L. (2010). La historia en el cine norteamericano. La ficción cinematográfica como (re)creación e interpretación del pasado. Lérida: Milenio.

Lara López, E. L. (2004). La religiosidad popular pasionista contemporánea (Jaén, 1859-1978): una historia a través de la fotografía como fuente documental. Jaén: Instituto de Estudios Giennenses.

Lara López, E. L. La fotografía como documento histórico-artístico y etnográfico: una epistemología (2005). Revista de Antropología Experimental, $\quad 5, \quad$ texto 10. http://www.ujaen.es/huesped/rae/articulos2005/lara2005.pdf.

López Hurtado, M. (2013). La tarjeta postal en España: usos y tendencias. Revista General de Información y Documentación, vol. 23, pp. 437453.

Man, R. (2013). La microhistoria como referente teórico-metodológico. Un recorrido por sus vertientes y debates conceptuales. Historia Actual Online, 30, pp. 167-173.

Martínez Gil, F. (2013). La historia y el cine: ¿unas amistades peligrosas?. Vínculos de Historia, 2, pp. 351-372.

Martínez Hernández, $M^{\mathrm{a}}$. J. (2005). Fuentes visuales para la Historia Contemporánea y del Arte. El orientalismo en Jaén (1897-1920). Boletín del Instituto de Estudios Giennenses, 190, pp. 387-420.

Martos Causapé, J. F. (2005). Del daguerrotipo al colodión. España a través de la fotografía del s. XIX. Berceo, 149, pp. 9-34.

Mattelard, A. (2004). Introducción a los estudios culturales. Barcelona: Paidós.

Marzal Felici, J. (2009). Cómo se lee una fotografía. Madrid: Cátedra.

Marzal Felici, J., Martín Núñez, M. y Soler Campillo, M. (2011). Tendencias e hibridaciones de la cultura visual contemporánea. Una visión panorámica de un proyecto de investigación en curso. adComunica. Revista de Estrategias, tendencias e Innovación en Comunicación, 2, pp. 119-136. 
Mulet $\mathrm{M}^{\mathrm{a}-J .}$ (2007). El acceso a la información sobre el patrimonio fotográfico en el Estado español. Revista Latente, 5, pp. 57-72.

Ortega López, T. Ma (ed.) (2007). Por una historia global. El debate historiográfico en los últimos tiempos. Granada-Zaragoza: Universidad de Granada-Prensa Universitarias de Zaragoza.

Pagès, P. (1988). Introducción a la Historia. Epistemología, teoría y problemas de método en los estudios históricos. Barcelona: Barcarola Temas Universitarios.

Palenque, M. (2013). Poesía, fotografía y tarjetas postales: Campoamor, Kaulak y Lázaro en la Serie M de la Colección Cánovas. Catálogo de la exposición Correspondencia sin privacidad: billetes, tarjetas postales y epístolas literarias en la Colección Lázaro Galdiano, pp. 85-103. Madrid: Fundación Lázaro Galdiano.

Palos, J. L. (2000). El testimonio de las imágenes, Pedralbes, 20, pp. 127142.

Pantoja Chaves, A. (2007): La imagen como escritura. El discurso visual para la Historia. Norba. Revista de Historia, 20, pp. 185-208.

Pantoja Chaves, A. (2008). Las fuentes de la memoria: la fotografía como documento histórico. En Nicolás, M. E. y González, C. (coords.) Ayeres en discusión. Murcia: Servicio de Publicaciones de la Universidad de Murcia.

Pons, A. (2010). Guardar como. La historia y las fuentes digitales. Historia Crítica, 43, pp. 38-61.

Pavao, L. (2001). Conservación de colecciones de fotografía. Sevilla: Instituto Andaluz de Patrimonio Histórico, centro Andaluz de Fotografía.

Pons, A. (2013). El desorden digital. Guía para historiadores y humanistas. Madrid: Siglo XXI.

Riego, B. (1996). La historiografía española y los debates sobre la fotografía como fuente histórica. Ayer, 24, pp. 91-111.

Riego, B. (2001). La construcción social de la realidad a través de la fotografía y el grabado informativo en la España del siglo XIX. Santander: Universidad de Cantabria.

Riego, B. (2011a). Una revisión del valor cultural de la tarjeta postal ilustrada en el tiempo de las redes sociales. Fotocinema, 2, pp. 3-18.

Riego, B. (ed.) (2011b). España en la tarjeta postal. Un siglo de imágenes. Barcelona: Lunwerg Editores.

Rioux, J-P. (1998). Historia del Tiempo Presente y demanda social. Ayer, 32, pp. 71-81.

Rodríguez de las Heras, A. (2009). Metodología para el análisis de la fotografía histórica. Espacio, Tiempo y Forma, Serie V, Historia Contemporánea, 21, pp. 19-35.

Sánchez Marcos, F. (2012). Las huellas del futuro. Historiografía y cultura histórica en el siglo XX. Barcelona: Universidad de Barcelona. 
Sánchez Vigil, Juan Miguel (1999). El universo de la fotografía. Prensa, edición, documentación. Madrid: Espasa.

Sánchez Vigil, J. M. (2006). El documento fotográfico. Historia, usos, aplicaciones. Gijón: Ediciones Trea.

Sanchidrián Blanco, C. (2011). El uso de imágenes en la investigación histórico-educativa. Revista de Investigación Educativa, 29 (2), pp. 295-309.

Serna, J. y Pons A. (2000). Cómo se escribe la microhistoria. Madrid: Ediciones Cátedra.

Serna, J. y Pons, A. (2005). La historia cultural. Autores, obras, lugares. Barcelona: Akal.

Tagg, John (2005). El peso de la representación. Ensayos sobre fotografías e historias. Barcelona: Gustavo Gili.

Traverso, E. (2007). El pasado, instrucciones de uso. Historia, memoria, política. Madrid: Marcial Pons.

Tribó Taveira, G. (2005). Enseñar a pensar históricamente. Los archivos y las fuentes documentales en la enseñanza de la Historia. Barcelona: Horsori.

Vega, J. de (2013). Del espectáculo de la ciencia a la práctica artística cortesana: apuntes sobre la fortuna de la fotografía en España. Revista de Dialectología y Tradiciones Populares, vol. XLVIII, pp. 359-383.

Velasco, $\mathrm{M}^{\mathrm{a}}$. J. (2011). La fotografía de la cultura popular a partir de la Transición española. Fotocinema, 2, pp. 56-74.

Vilar, P. (1980). Iniciación al vocabulario de análisis histórico. Barcelona: Crítica.

Visa Barbosa, M. (2012). Una metodología sociológica y narrativa para el análisis de relatos fotográficos. Estudios sobre el mensaje periodístico, 18, pp. 929-939.

Zaragoza Bernal, J. M. (2013). Historia de las emociones: una corriente historiográfica en expansión. Asclepio, 65 (1): e012. doi: http://dx.doi.org/10.3989/asclepio.2013.12

Cómo citar: Lara López, E. L. (2015). "El historiador y la fotografía: una relación antropológica”. Fotocinema. Revista científica de cine y fotografía, 10, pp. 75-99. Disponible: http://www.revistafotocinema.com/index.php?journal=fotocinema\&page=article\&op =view \&path []$=278$ 